\title{
O SENTIDO JURÍDICO BRASILEIRO REFLEXÕES PARA UMA TEORIA POLÍTICA E JURÍDICA A PARTIR DE "O POVO BRASILEIRO" DE DARCY RIBEIRO
}

\author{
Alysson Leandro Mascaro \\ Pesquisador de Filosofia do Direito da USP \\ Professor da Faculdade de Direito da Universidade Mackenzie
}

\begin{abstract}
Resumo:
A partir da obra de Darcy Ribeiro "O Povo Brasileiro" busca-se empreender uma reflexão jurídica que tenha por base a formação e o sentido do Brasil. Um pensamento e uma estruturação jurídica que atendam à formação e à situação brasileira devem ser feitos tendo por base a própria constituição do povo e do sentido brasileiro, sem as fórmulas tradicionais e inadequadamente aplicadas à realidade nacional.
\end{abstract}

\begin{abstract}
:
Starting from Darcy Ribeiro work "O Povo Brasileiro" is looked for to undertake a juridical reflection that has for base the formation and the sense of Brazil. A thought and a juridical structuring that assist to the formation and the Brazilian situation they should be done tends for base the own constitution of the people and of the Brazilian sense, without the traditional formulas and inadequately applied to the national reality.
\end{abstract}

Unitermos: Darcy Ribeiro, obra; sentido jurídico brasileiro.

Se o balanço de quinhentos anos de Brasil serve de momento de reflexão, ela não pode ser feita sem a autenticidade que se exige de um povo que teima em ser feliz e justo e que historicamente construiu-se no eito de sofrimento e injustiça. No bojo de uma consciente e crítica perspectivação histórica brasileira, as questões de Direito e Justiça ainda hoje restam, em geral, maltratadas e, às vezes, conscientemente relegadas a plano inferior. Se pensarmos que quinhentos anos de Brasil são também quinhentos anos de injustiça, e quinhentos anos de invenção de Justiça de um povo, veremos o quanto ainda nos falta vasculhar, no interior de nós mesmos e de nosso povo, a fim de descobrirmos a vastidão e a amplitude do fenômeno juridico em nossa experiência e em nossa formação, ao mesmo tempo em 
que nos falta criar instrumentais jurídicos que podem nos formar. A construção de uma civilização brasileira digna e honrada somente será feita se também passar, por seu balanço, a reversão do quadro histórico de injustiça, o que se faz tendo o passado como dado existente para a transformação do futuro.

A academia e os intelectuais brasileiros, no entanto, historicamente se encontraram ligados aos poderes e regimes de ampla injustiça que nos formaram e que devem ser objeto de crítica. Salvo poucas exceções, a cultura nacional - e também em um certo sentido a cultura jurídica - foram constituídas no Brasil como verniz de refinamento educacional, sem autonomia nem vitalidade própria. Os padrões de pensamento europeu, ao seu turno, serviram de apoio à construção de uma certa ordem nacional, formando uma barreira ideológica contra a manifestação independente e autônoma do pensamento nacional, olvidando-se das questões nacionais em troca das metafísicas culturais externas. Tal sentido colonizador, e tal invasão do pensamento da metrópole nos intelectuais da colônia, resultaram num quadro em que não se vê, historicamente, na nacionalidade brasileira, a academia preocupada com seu povo, mas sim. em se justificar aos poderes que, desde então, têm por sentido e orientação a exploração nacional. Este quadro, ainda até hoje, é gravemente reinante.

As tentativas de autonomia nacional, no entanto, sempre existiram e foram tentadas muito mais de maneira individual e isolada que propriamente de corpos de pesquisadores e estudiosos ou de universidades e instituições de ensino. Num certo sentido, diz-se sobre o pensamento brasileiro como se se tratasse do estudo que tem por objeto o próprio país. Isto, no entanto, nada representa em termos objetivos, pois que, na maior parte dos casos, os métodos e os encaminhamentos das reflexões tinham por instrumentais os externos, de tal modo que, mesmo em se tratando de estudar o Brasil, os olhares eram de estranhos. Isto nos explica também que não-basta termos filósofos brasileiros - nascidos ou moradores no Brasil - para que tenhamos filosofia brasileira, nem que basta termos juristas debruçados sobre as leis nacionais para que tenhamos um pensamento jurídico brasileiro. A bem dizer, não-bastam os pés plantados no país e a cabeça de subjugado, é preciso um banho de brasilidade, de experiência, de necessidades e carências de nossa gente, a fim de que comecemos a pensar a própria civilização brasileira, sob risco de, procedendo em contrário, não podermos nem tê-la como realidade, quanto mais como objeto de estudo. Urge, pois, depois de cinco séculos de nós mesmos, estudarmos e sermos nós mesmos. 
O século $X X$ viveu, principalmente em seu período intermédio, uma tentativa, em várias áreas, de construção de uma consciência nacional. No Direito, muito pouco se viu em tal direção, e as poucas tentativas jurídicas deram-se muito mais em demandas concretas - os primeiros pensadores brasileiros dos direitos sociais, por exemplo, ou aqueles que lutaram pelos direitos fundamentais em épocas de ditadura - que propriamente no plano epistemológico ou puramente intelectivo. No campo das ciências sociais, no entanto, há um número maior de pensamentos que se pretenderam nacionais, alguns deles já cotejados em direção a uma aplicação jurídica, outros ainda necessitando de maiores reflexões concretas. Neste caso se insere a obra, dentre outros, de Darcy Ribeiro.

\section{O Povo Brasileiro}

O Povo Brasileiro, ${ }^{1}$ obra de Darcy Ribeiro escrita em vésperas de sua morte, pretende inserir-se no grande quadro de "teorias" do Brasil, que em meados deste século conheceu autores do porte de Sérgio Buarque de Holanda ou Gilberto Freyre. O Povo Brasileiro, no entanto, aliando-se a este projeto geral de explicação do Brasil, parte da premissa de uma explicação brasileira para o fenômeno brasileiro, e uma explicação participativa, o que leva, nas próprias palavras de Darcy Ribeiro, a uma visão científica "movida por razões éticas e um fundo patriotismo" $\mathrm{Na}$ verdade, a originalidade do pensamento de Darcy Ribeiro é daí que ressalta. A análise antropológica da formação de "uma nova Roma" lavada em sangue negro e índio, é parte de um conjunto de constatações singulares de um pensamento que, ao contrário de uma perspectiva tradicional do historicismo marxista ou da antropologia européia, congrega em sua reflexão o fator nacional, o modo de ser próprio do povo brasileiro, sem cair nos riscos próprios de um pensamento conservador de moldes nacionalistas ou patrióticos, de baixo grau de consistência científica. Mais que uma plena explicação do Brasil, talvez seja a obra de Darcy Ribeiro um sempre oportuno convite à reflexão, à compreensão e à prática da construção de caminhos brasileiros.

1. Ribeiro, Darcy. O Povo Brasileiro. A formação e o sentido do Brasil. $2^{a}$ ed. São Paulo, Companhia das Letras, 1996. 
O esforço para uma reflexão brasileira

Não se pode confundir, na motivação da obra de Darcy Ribeiro, o objeto de estudo com a sua metodologia. O povo brasileiro, a formação e o sentido do Brasil são objetos de estudo já há muito motivadores das mais diversas reflexões, tanto nacionais quanto internacionais, e talvez não seja em tal ponto que resida embora nos dias atuais destaque-se pela escassez de estudos sérios sobre o Brasil - a originalidade da proposta de $O$ Povo Brasileiro. A sua grande motivação, e a sua busca de diferenciação, na verdade, é a construção de uma nova perspectiva de análise. Não se trata, em hipótese alguma, de modificar as ênfases do objeto de estudo - a realidade brasileira sob a perspectiva econômica, estrutural ou social -, mas sim de aventurar-se a nova façanha, que é a de elaborar uma reflexão brasileira sobre o fenômeno brasileiro, sem os vícios da experiência intelectual européia, da qual se abeberaram os intelectuais e acadêmicos brasileiros durante longo período, $\mathrm{e}$ cujas constatações finais não parecem por justo adequadas à realidade brasileira. Na verdade, conceitos como o de liberalismo, burocracia e intervencionismo passam ao largo da expressão mais verdadeira da realidade do povo brasileiro, servindo apenas como elemento de diálogo com situações que, muito embora essencialmente ligadas às metrópoles e o que determinavam à realidade brasileira, não significavam necessariamente o fenômeno vivido na situação nacional.

Proceder a uma análise brasileira talvez seja, em primeiro momento, o grande esforço e o grande perigo da condução das reflexões da obra. Isto porque uma análise brasileira, que leve em conta a originalidade nacional, reveste-se de potenciais riscos de incompreensão ou de paixão irracionalizada. A constatação, feita logo na Introdução pelo autor, de uma "uniformidade cultural e unidade nacional" desprovida, certamente, de ranços próprios de uma mentalidade nacionalista imperial, encontra-se numa tênue situação explicativa, tendo em vista a tentadora opção ufanista envolvente em tais discursos. No entanto, apressa-se 0 autor (p. 23) a enfatizar uma certa frieza de análise da questão da unidade e da uniformidade do povo brasileiro, ao mostrar as causas, o custo e o processo de uniformização, subjugadores e massacrantes das culturas populares, principalmente da indígena e da africana. Mesmo assim, ainda, há os resultados de tais processos, e furtar-se a considerá-los - ou até mesmo a valorá-los , sob pretensas necessidades críticas, seria proceder à frieza dos métodos importados para a compreensão de uma 
realidade própria. Assim procede o autor na tentativa de levantar os pilares de uma apreensão de fato brasileira do fenômeno brasileiro.

O processo civilizatório

Sob este nome Darcy Ribeiro escreveu uma de suas obras que pretendeu unir a outras de sua lavra, sob um título geral Estudos de antropologia da civilização. O desenvolvimento de $O$ Povo Brasileiro segue também estas trilhas. Suas três primeiras seções são todas elas destinadas a refletir sobre este processo de formação nacional, o processo civilizatório brasileiro.

A constituição deste processo civilizatório se faz sobre as bases dos povos indígenas já estabelecidos no território que no século XVI passa a ser invadido, com alta dose de força e mesmo truculência, pelos invasores lusos. Os povos indígenas do litoral, fundamentalmente do tronco Tupi, constituiam, a essa época, uma população que beirava talvez um milhão de índios. Portugal, à época, tinha uma população de mesma quantidade. Os povos Tupi, nesta fase, superavam a condição paleolítica e procediam aos primeiros passos de uma revolução agrícola. Mudando sua rota, no entanto, deu-se fato novo que "foi a introdução no seu mundo de um protagonista novo, o europeu (...) capaz de atuar destrutivamente de múltiplas formas" com um conflito "em todos os niveis, predominantemente no biótipo" (p. 30). Os portugueses, aliados à Igreja e suas necessidades de roupagem evangelizadora, puseram-se em enfrentamento do mundo novo. $\mathrm{O}$ resultado desta oposição pode-se a ver nos versos de louvação escritos pelo próprio padre José de Anchieta, sobre os feitos de Mem de Sá contra os índios (p. 50):

Quem poderá contar os gestos heróicos do Chefe;

à frente dos soldados, na imensa mata;

Cento e sessenta as aldeias incendiadas;

Mil casas arruinadas pela chama devoradora;

Assolados os campos, com suas riquezas;

Passado tudo ao fio da espada. 
Por povos germinais trata Darcy Ribeiro aqueles que, como os árabes em seu longo poderio medieval, a Roma antiga e outros povos como os ingleses posteriormente, plantaram-se, de maneira surpreendente, com energia expansiva, como os ibéricos na época do início deste processo civilizatório brasileiro, em terras novas. Resultados vão sendo produzidos neste processo. Atuando com a ética do aventureiro, que improvisa a cada momento diante do desafio que tem de enfrentar, os iberos não produziram o que quiseram, mas o que resultou de sua ação, muitas vezes desenfreada" (p. 70). Sobre o senhorio natural do cristão sobre o índio, "tal éa força desta ideologia que ainda hoje impera, sobranceira. Faz a cabeça do senhorio classista convencido de que orienta e civiliza seus serviçais, forçando-os a superar sua preguiça inata para viverem vidas mais fecundas e mais lucrativas. Faz, também, a cabeça dos oprimidos, que aprendem a ver a ordem social como sagrada e seu papel nela prescrito de criaturas de Deus em provação, a caminho da vida eterna" (p. 72).

Somando-se a este processo inicial, continua o processo civilizatório brasileiro quando, mais tarde, vêm se somar ao criatório de gente os negros africanos. A brutalidade da sua submissão, a passividade a qual foram impelidos, são marcas do moinho de gastar gente que vai constituindo a civilização brasileira. A mais terrivel de nossas heranças é esta de levar sempre conosco a cicatriz de torturador impressa na alma e pronta a explodir na brutalidade racista e classista. Ela é que incandesce, ainda hoje, em tanta autoridade brasileira predisposta a torturar, seviciar e machucar os pobres que Ihes caem às mãos" (p. 120). Darcy Ribeiro chega a estimar "que o Brasil, no seu fazimento, gastou cerca de 12 milhões de negros, desgastados como a principal força de trabalho de tudo o que se produziu aqui e de tudo que aqui se edificou. Ao fim do periodo colonial, constituía uma das maiores massas negras do mundo moderno" (p. 221).

O resultado desta gestação, pode-se ver após três séculos, quando em 1850 " o produto real do processo de colonização já era, naquela altura, a formação do povo brasileiro e sua incorporação a uma nacionalidade étnica $e$ economicamente integrada" (p. 159). A empresa Brasil, economicamente, formavase por meio de quatro ordens de ação empresarial. A primeira delas, e a mais rentável, a empresa escravista. A segunda, a empresa comunitária jesuítica. A terceira, a produção de gêneros de subsistência e de criação de gado. A quarta delas, a da intermediação comercial e portuária entre o Brasil, a Europa e a África. 
Ao processo civilizatório brasileiro, com o passar do tempo, vai se constituindo um grande fenômeno de urbanização e, imediatamente em seguida, uma grande deterioração urbana (p. 204), tudo somado, neste meio termo, à imigração em massa de outras populações, principalmente a européia. Ao contrário de países como a Argentina, em que o europeu imigrante constituiu-se em quatro quintos da população local, abolindo a cultura antiga e construindo a sua própria em terra alheia - transfigurando-os de povos novos a povos transplantados -, "o Brasil nasce e cresce como povo novo, afirmando cada vez mais essa característica em sua configuração histórico-cultural" (p. 243).

O povo que se constrói, neste processo civilizatório, está sendo feito sob um motor de originária anarquia, pretensamente ordenada sob os ditames da civilização européia e do caminho pretensamente certo da evangelização. $A$ contrapartida dialética da intencionalidade do projeto colonial é o caráter anárquico, selvagem e socialmente irresponsável da expansão dos núcleos brasileiros. Atuando sobre uma realidade diferente, que obrigava a buscar soluções próprias ajustadas à sua natureza e agindo longe das vontades oficiais, a ação do colono exerceu-se quase sempre improvisadamente e ao sabor das circunstâncias. Sendo imprevisível, ela crescia desgarrada até que, por reiteração, constituísse uma pauta de ação suscetível de ser regulada e copiada" (p. 245).

Os brasis na história

Darcy Ribeiro devota a quarta unidade de sua obra à análise daquilo que denomina "ilhas-Brasil" cenários regionais que, na verdade, são expressão substancial do processo de formação da brasilidade, que apenas de maneira esquemática e esparsa consegue ser abrangido por meio de teorizações de planificação geral. A estas ilhas-Brasil, indicadas em $O$ Povo Brasileiro "como núcleos aglutinadores e aculturadores dos novos contingentes apresados na terra" (p. 270), estendiam-se "três redes aglutinadoras: a identidade étnica, (...) a estrutura socioeconômica colonial de caráter mercantil, e (...) uma nova tecnologia produtiva, que as ia tornando mais e mais complexas e dependentes de artigos importados. Sobre todas elas falava uma incipiente cultura erudita, principalmente religiosa, de padrão básico, que se ia difundindo" (p. 271). 
Destas ilhas-Brasil, comenta o próprio Darcy Ribeiro em suas sínteses: "Elas são representadas pela cultura crioula, que se desenvolveu nas comunidades da faixa de terras frescas e férteis do Nordeste, tendo como instituição coordenadora fundamental o engenho açucareiro. Pela cultura caipira, da população das áreas de ocupação dos mamelucos paulistas, constituída, primeiro, através da atividade de preia dos índios para a venda, depois, da mineração do ouro e diamantes e, mais tarde, com as grandes fazendas de café e a industrialização. Pela cultura sertaneja, que se funde e difunde através dos currais de gado, desde o Nordeste árido até os cerrados do Centro-Oeste. Pela cultura cabocla das populações da Amazônia, engajadas na coleta de drogas da mata, principalmente nos serigais. Pela cultura gaúcha do pastoreio nas campinas do Sul e suas duas variantes, a matuta-açoriana (muito parecida com a caipira) e a gringo-caipira das áreas colonizadas por imigrantes, predominantemente alemães e italianos" (p. 272).

O próprio Darcy Ribeiro resume tais ilhas-Brasil, elementos celulares deste grande processo de civilização brasileiro (p. 273): É simplesmente espantoso que esses núcleos tão iguais e tão diferentes se tenham mantido aglutinados numa só nação. Durante o período colonial, cada um deles teve relação direta com a metrópole e o 'natural' é que, como ocorreu na América hispânica, tivessem alcançado a independência como comunidades autônomas. Mas a história é caprichosa, o 'natural' não ocorreu. Ocorreu o extraordinário, nos fizemos um povo-nação, englobando todas aquelas províncias ecológicas numa só entidade cívica e política"

\section{O Destino Nacional}

Talvez resida, na última parte de $O$ Povo Brasileiro, a sua maior grandeza, altivez, inspiração e originalidade. Nela, Darcy Ribeiro explicita o nervo condutor das análises situacionais, antropológicas e históricas sobre as quais se debruçou nas unidades antecedentes. Feito a princípio como "uma feitoria escravista' (p. 446), o Brasil construiu-se com enorme apoio na "primazia do lucro sobre a necessidade" Esta formação econômica de feitoria, que é extremamente lucrativa em termos empresariais aos grupos exploradores, vindos e interessados de fora, mantém, ao mesmo tempo, "uma penúria generalizada da população local" 
O povo brasileiro, que se constitui neste processo novo de civilização, não mantém laços divergentes das origens que o formaram, não havendo etnia hegemônica ao ponto de romper a unidade étnica nacional. A separação do povo brasileiro, ainda, não é a da origem, mas sim a da estratificação de classes. "Não há, nunca houve, aqui um povo livre, regendo seu destino na busca de sua própria prosperidade. O que houve e o que há é uma massa de trabalhadores explorada, humilhada e ofendida por uma minoria dominante, espantosamente eficaz na formulação e manutenção de seu próprio projeto de prosperidade, sempre pronta a esmagar qualquer ameaça de reforma da ordem social vigente" (p. 452).

A perspectiva brasileira da realidade nacional, em Darcy Ribeiro, conduz à perspicaz, ao mesmo tempo em que lúcida, análise dos novos povos, em especial o americano, e a formação do processo civilizatório de cada qual. Ao passo que a América Andina, Mexicana e do Altiplano enfrentam o dilema de uma fusão entre duas civilizações milenares que devem se construir em outra nova, a América do Norte e a América Austral branca nada mais são, neste processo civilizatório, do que o transplante, para novas terras, do mesmo povo europeu e anglo-saxão para o caso dos da América do Norte. No Brasil, em seu povo e em sua formação, residem novas tarefas. Um povo em fazimento, que não se pode reger pelas regulações nem tampouco pela cartilha dos passos dos povos que já de outro modo se constituem, mas, sim, um povo novo, uma tarefa mais complexa que a de reprodução, que é, nas próprias palavras de Darcy Ribeiro, "o desafio de reinventar o humano, criando um novo gênero de gentes, diferentes de quantas haja"

"Um povo em ser, impedido de sê-lo" Ao mesmo tempo em que a análise de $O$ Povo Brasileiro, desprovida da necessidade europeizante, academicista e intelectualista das constatações negadoras do pulsar da brasilidade para trocá-lo por padrões de racionalidade tecnicista desconhecidos, é um aprendizado intelectual que não se restringe ao confrontamento meramente informativo, mas sim é uma arma intelectiva a ressoar nas estruturas mais dignas e nobres que movem o espírito humano, é também um canto de amor a um povo, a uma gente, à humanidade e sua beleza, e tais situações conduzem não só à frieza das constatações e das explicações, mas sim à grandeza do impulso, que se pode construir na realidade intelectiva, na conscientização e na tomada de posição política em face da humanidade, de um povo e de suas necessidades, fundamentalmente a necessidade - ainda ora impedida - de ser. 
A formação do Direito e o sentido jurídico do Brasil

Não nos é possível - quer pela consciência crítica quer pela ordem das coisas - tratar das questões de Direito e Justiça que nos envolvem sem termos por substrato o processo histórico que nos dá base. É por meio dele que o pensamento e a prática do Direito começam a nos conformar como um pulsar de dor e injustiça, de clamor de Direito, de Direito e Justiça enfim. Talvez no limiar de uma nova época, uma nova consciência jurídica desperte como proposta de uma situação jurídica nova.

As maiores injustiças de nosso povo, além das atrocidades judiciárias desde sempre havidas, são, fundamentalmente, as originárias, aquelas das estruturas basilares que nos formaram e que ainda hoje nos constituem. Ao observarmos que, nas palavras de Darcy Ribeiro, no início aqui se deu um "enfrentamento" de brancos contra índios nas terras destes, observamos o quanto ainda tapamos os olhos para a nossa realidade e construímos a história - e a história jurídica - dos poderes que reinam e vencem e não daqueles que conclamam Justiça. Os negros e seus martírios até hoje presentes são marcas que teimamos em desconsiderar, mas que batem à porta da estrutura própria da nacionalidade em busca de uma resolução. Por fim, ainda hoje nossa técnica e o melhor de nosso pensamento jurídico se voltam às questões mais sensíveis e caras de uma estrutruração jurídica que atende às meras necessidades dos poderes econômicos e produtivos estabelecidos, na confluência das necessidades produtivas apátridas com os interesses dos poderes aqui estabelecidos, e mais uma vez constitui-se a história jurídica de exploração do povo brasileiro. No entanto, é hora de vencermos etapa também no mundo jurídico.

Trata-se, fundamentalmente, hoje, de conseguirmos obter a essência mais verdadeira de nossa brasilidade e de nossa estruturação justa nacional, sem os padrões de uma cultura importada nem os padrões dos interesses de poder estabelecidos, mas sim de uma constante reinvenção. O Direito, em quinhentos anos desta nossa história, serviu muito mais para a injustiça e para a compressão de gentes escravas em um território novo, mas nos deu também o impulso e o apelo para a formação de nossa consciência do justo. Como a história se faz também das estruturas mais profundas de uma gente, a alegria brasileira de sempre vir-a-ser nos torna ainda esperançosos e vitalizados para sermos um povo no mundo com a alegria da Justiça que não nos foi dada, mas construída. Daí o impulsc conscientizador de $O$ Povo Brasileiro, daí o seu brado, de conhecimento de si 

brasileiro", de Darcy Ribeiro

mesmo de um povo, mas fundamentalmente de amor e de presença deste mesmo povo e de sua gente, uma nova Roma, uma nova civilização. "Mais alegre, porque mais sofrida. Melhor, porque incorpora em si mais humanidades. Mais generosa, porque aberta à convivência com todas as raças e todas as culturas e porque assentada na mais bela e luminosa província da Terra" 